\title{
Long-term portfolio investments: New insight into return and risk
}

\author{
Alexander Abramov ${ }^{\mathrm{a}, *}$, Alexander Radygin ${ }^{\mathrm{a}, \mathrm{b}}$, \\ Maria Chernova ${ }^{a}$ \\ ${ }^{a}$ Russian Presidential Academy of National Economy and Public Administration, Moscow, Russia \\ ${ }^{b}$ Gaidar Institute for Economic Policy, Moscow, Russia
}

\begin{abstract}
This article analyzes the impact of the increase of an investment horizon on the comparative advantages of the basic asset classes and on the principles of constructing the investment strategy. It demonstrates that the traditional approach of portfolio management theory, which states that investments in stocks are preferable over bonds in terms of their long-run risk-return trade-offs, is by no means always consistent with empirical evidence. This article proves the opposite, i.e., that for long-term investors, investments in corporate bonds are more profitable in terms of the risk-return ratio than investments in stocks, arguing in favor of strategies pursued by pension funds and other institutional investors focused primarily on investments in fixed-income instruments, including infrastructural bonds.

Emphasis is placed on the need for regular adjustments to long-term investors' portfolios. As portfolios get older, those investors see a reduction in the returns' dispersion, while differences in risk between various portfolios increase. This means that to maintain a fixed risk-return ratio for a portfolio as the horizon increases, an investor needs to increase the share of lower-risk financial assets during asset allocation process. This thesis becomes especially relevant in the context of retirement savings management.

(C) 2015 Non-profit partnership "Voprosy Ekonomiki”. Hosting by Elsevier B.V. All rights reserved.
\end{abstract}

JEL classification: D14, G11, G12, G15, G17, G23, H55

Keywords: retirement savings, long-term investments, investment horizon, stock and bond returns, stock and bond investment risks, portfolio diversification.

\footnotetext{
th The updated English version of the article published in Russian in Voprosy Ekonomiki, 2015, No. 10, pp. 54-77.

* Corresponding author, E-mail address: ae_abramov@mail.ru.

Peer review under responsibility of Voprosy Ekonomiki.
} 


\section{Introduction: The traditional theory of the advantages of long-term investments}

The Russian Government's decision to preserve mandatory retirement savings $^{1}$ and the deficit of private investment in long-term infrastructural projects highlights the problem of the efficiency of various classes of investment assets in the portfolios of institutional investors in terms of the risk-return trade-off. Abramov et al. (2014) and Radygin (2015, pp. 275-342) emphasized the need for the rational integration of long-term money investments in the formation of the rules of supervision and regulation of institutional investors. At the same time, the degree of rigidity of constraints on the composition and structure of assets of pension funds as well as the configuration of the system of prudential supervision should be more responsive to the level of return and risk of different groups of financial assets (Abramov et al., 2015).

The impact of the increase of the investment horizon on changes in the riskreturn profiles of various financial instruments and portfolios has also become a topical issue. The existing research substantiates various assumptions regarding possible ways to improve a portfolio's risk-return profile by diversifying investments in various financial instruments and increasing the investment horizon. The classical papers by G. Markowitz $(1952,1995)$ and W. Sharp (1970) prove the possibility for considerably improving the risk-return profile of a portfolio through diversification and propose an algorithm for selecting the best portfolio for various investors. One of the assumptions - closely associated with the idea of the CAPM model portfolio diversification - is that investors make investments for the same investment horizons and view the behaviors of various financial assets similarly. According to these theories, adding securities with different return correlations to a portfolio may produce a diversification effect, i.e., it may mitigate the portfolio risks without prejudice to returns, improve returns without increasing the risks, or produce a combination of both effects.

A great deal of research is dedicated to the "return decomposition theory", which studies the role of various factors in the risk-return profiles of institutional investor portfolios. In particular, Brinson et al. $(1986,1991)$ demonstrated that $90 \%$ of the volatility in the total returns of a pension fund is determined by the asset allocation. Similar results are presented in studies by Sharpe (1992) and Ibbotson and Kaplan (2000).

These papers introduced a rule in portfolio management practice that states that foremost attention should be paid to asset allocation rather than active management. Using the example of retirement savings portfolios for private Russian pension funds (PPF) and mutual funds, Abramov and Chernova (2015) showed that only one-fourth of the PPF's returns and one-third of open-ended and interval mutual funds' returns are determined by active management strategies, with the rest depending on asset allocation.

One of the most thoroughly researched problems is that of the so-called premium on stock holding, which was first actively discussed in academic litera-

\footnotetext{
1 At the session of the Russian Federation Government on April 23, 2015, Prime Minister D. Medvedev made an official statement that "the decision has been made: the saving component stays." See shorthand notes of reports from this session at http://government.ru/meetings/17789/.
} 
ture during the 1960s, almost concurrently with the efficient market hypothesis. Having analyzed long-term series of returns for various financial instruments, most researchers came to the consensus that stock holding, as a rule, provides a positive premium for investors, as opposed to returns on safe bonds. ${ }^{2}$

However, the shortcoming for most of the above papers is their insufficient focus on the risks of investing in different financial instruments. A consistent comparison between stocks and bonds based on risk and return factors over different horizons was attempted by J. Siegel (2008) in his "Stocks for the long run: The definitive guide to financial market returns and long-term investment strategies." The research was based on statistics on annual returns for U.S. stocks, treasury bonds and bills during the period 1802 to 2006 .

We will underscore the following important aspects of Siegel's (2008) work. Increasing investment periods reduce the variation between average returns on financial instruments, while the difference between maximum and minimum returns decreases faster for stocks than for fixed-income securities as the length of holding increases (Fig. 1). His calculations used stocks, treasury bills and bonds on the U.S. stock market. Returns on stocks take into account dividends accrued. The graph shows that for 20-year investment horizons, the minimum return on a stock portfolio becomes positive at $1.0 \%$, while the minimum return on bonds and treasury bills remains negative at $-3.1 \%$ and $-3.0 \%$, respectively.

The risks inherent in financial instruments decrease as the horizon increases. According to Siegel, the standard deviation of average annual returns is negatively correlated to the holding period, provided that returns on assets are consistent with the random walk hypothesis. An analysis of actual series of stock, bond and treasury bill returns in the United States from 1802 to 2006 shows that starting from 20-year holding periods, the standard deviation (risk) for stocks becomes lower than for bonds and even treasury bills.

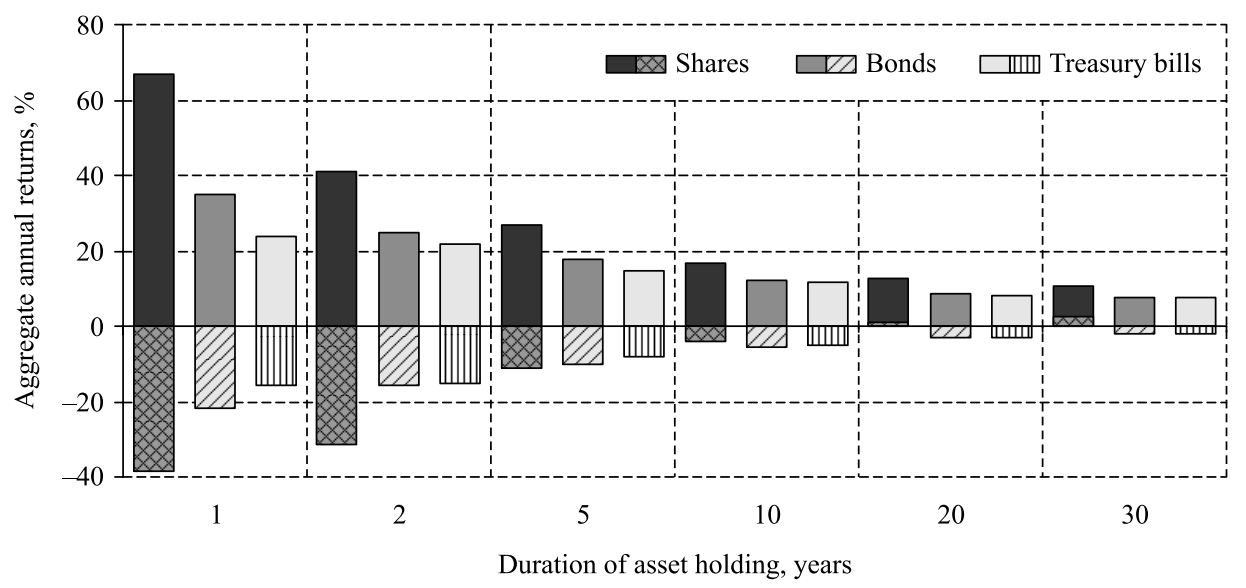

Fig. 1. Maximum and minimum returns for different holding periods, 1802-December 2006. Source: Siegel (2008, p. 25).

\footnotetext{
2 This viewpoint has been formulated by Fisher and Lorie (1964), Mehra and Prescot (1985), Poterba and Summers (1988), Siegel (1992, 1999, 2005), Robertson and Wright (1998), Ibbotson and Chen (2003), Ilmanen (2003), DeLong and Magin (2009), etc.
} 
Thus, having compared risk-return profiles for portfolios with different horizons, Siegel came to the conclusion that "the safest long-term investment for the preservation of purchasing power has clearly been a diversified portfolio of equity" (Siegel, 2008, p. 25).

Siegel's methods of analyzing the risks and returns of stocks and bonds in the U.S. and several other developed markets have also been examined for Russian stock market securities. Based on data for stock and bond returns in the U.S. market for the period 1928 to 2008, Berzon and Teplova (2013) demonstrated that increasing the holding periods of securities from one to 30 years leads to insignificant changes in average annual returns on stocks and bonds, while the standard deviation of stock returns decreases faster than bond returns over longer investment periods. Having compared monthly returns of the MICEX index with the Rux-Cbonds (currently IFX-bonds) index of safe corporate bonds for the period from January 1, 2002, to October 1, 2009, they found that a longer investment period reduces the spreads of minimum and maximum monthly returns on these financial instruments and that stock spreads decrease faster than bond spreads. However, the short period reviewed did not allow the time interval - which makes stocks preferable to bonds in terms of their risk-return ratios - to be identified (Berzon and Teplova, 2013, p. 277).

Without contesting the correctness of these findings, we note, however, that they contain some assumptions that reduce their practical utility for institutional investors in building their portfolios. Moreover, they may lead to an incorrect understanding of the methods for building optimized portfolios. To substantiate his findings, Siegel used the following method to calculate average risks and returns for stock and bond portfolios over different horizons. Over a period spanning 205 years from 1802 to 2006, aggregate portfolios were built with different investment horizons, from 1 to 100 years. ${ }^{3}$ An average annual return was calculated for each aggregate stock and bond portfolio with the same horizon. Then, risk was determined as the standard deviation of the series of average returns. In other words, the focus here was not on the risk-return profile of each particular portfolio with a certain horizon but on the indicators calculated based on an aggregate of portfolios with the same investment period that could have been built if the investment period of the investor had been 205 years. This fact makes Siegel's findings somewhat conventional, as this approach can hardly be applied by actual investors in practice. Real investors are more concerned with the problem of risks and returns for one or, at most, several portfolios than, for example, with the average indicators of 2005 -year portfolios built over 205 years.

At the same time, those who actually manage long-term portfolios for pension and mutual funds will be surprised to learn that their real portfolios behave differently: as the horizon increases, the average annual return does actually decrease, whereas the standard deviation of the portfolio is, on the contrary, most likely to increase. For example, according to the 2014 annual report of GPFG (Norway), which is one of the world's largest government pension funds, the average annual returns on its portfolio for 1,5 and 10 years was $7.58 \%, 8.61 \%$ and $6.14 \%$, respectively, while the standard deviations for the same periods were $4.57 \%, 7.24 \%$ and $8.59 \%$. As the horizon grew, the real portfolio of the pension

\footnotetext{
${ }^{3}$ For the period from 1802 to 2006, 200 5-year, 185 20-year and 105 100-year portfolios could be built.
} 
fund showed a noticeable increase in the standard deviation, but by no means its reduction. Contrary to the assumptions about the benefits of long-term investment in stocks compared with bonds, one can note that in many countries, investments in bonds are the greatest in the structure of assets of pension funds. This fully applies to the portfolios of pension savings in pension funds and management companies in Russia (Abramov, 2014, pp. 404-408). We will show below that it is not just the specific behavior of an individual pension fund portfolio but a problem that is more systemic in nature, thus raising questions about Siegel's and other later researchers' findings based on their calculations.

\section{Diversification opportunities over a medium-term investment horizon (up to 10 years)}

This paper explores the impact of increased investment horizons on the effectiveness of asset management, based primarily on an analysis of the risks of longterm asset allocation strategies. The classical theory argues that risk is mitigated as the investment period increases. However, uncertainty about future returns (and, consequently, the ultimate return on the same portfolio) will only grow. The longer the investment period, the higher the probability of various extreme and rare events, such as a global crisis or a crash in a particular financial market. Such events may lead, for example, to short-term negative returns on assets within a portfolio and to losses. This, in turn, may result in increased volatility of returns and ultimately reduced returns. The basic assumption examined in the analysis is that risks and returns behave differently rather than converge, as Siegel shows in his works.

In the empirical analysis, an example of the fullest global diversification of a portfolio was reviewed. To this end, we selected stocks for U.S. ETFs using different investment strategies as well as several stock market indices in a number of countries. This approach produced relevant and sustainable results, taking into account data from one of the most diverse samples of assets possible, along with the opportunities provided by various investment strategies pursued by ETFs and financial markets in developed countries and in Russia. We selected the following 19 instruments, for which we gathered historical series of their daily returns over 10 years (2004-2014), based on Bloomberg data: ${ }^{4}$

1. SPDR S\&P 500 ETF;

2. iShares Latin America $40 \mathrm{ETF}$;

3. iShares 1-3 Year Treasury Bond ETF;

4. Vanguard Small-Cap ETF;

5. iShares North American Natural Resources ETF;

6. SPDR S\&P 600 Small Cap Value ETF;

7. iShares iBoxx \$ Investment Grade Corporate Bond ETF;

8. iShares 7-10 Year Treasury Bond ETF;

9. iShares Russell 2000 Value ETF;

10. iShares S\&P 500 Growth ETF;

11. iShares MSCI EAFE ETF;

12. SPDR Gold Trust;

13. iShares Transportation Average ETF;

${ }^{4}$ The Bloomberg Professional service (the Terminal). Official website: http://www.bloomberg.com/. 
14. iShares Nasdaq Biotechnology ETF;

15. CAC Index (France);

16. FTSE-100 Index (UK);

17. NKY Index (Japan);

18. DAX Index (Germany);

19. RTSI Index (Russia), currency. ${ }^{5}$

The analysis covered three different investment periods: 1,5 and 10 years. This enabled us to review changes in the intertemporal characteristics of potential portfolios over short, medium and long periods of time. Table 1 contains the values of the sample mean value of annual returns for all sampled assets and for each time interval. We can see that the average returns on individual instruments demonstrate the predicted theoretical reduction for only a few of the instruments. These include the following ETFs: SHY US Equity (an investment-grade U.S. bond fund), LQD US Equity and IEF US Equity (medium and long-term U.S. government bond funds), IVW US Equity and IWN US Equity (growth and value stock funds), IYT US Equity and IBB US Equity (transportation and biotechnology funds).

Thus, only approximately half of the sampled instruments showed a noticeable reduction in returns over increasing investment periods. The other indices and funds showed either no such trend or, in some cases, even showed an increase in the mean value. For example, the Russian and French indices (RTSI and CAC, respectively) demonstrated sharply negative returns in 2013 and 2014, which corresponds to an annual period in this analysis. However, they showed quite highly positive returns when the period was expanded to 2004-2014. Thus, we cannot

Table 1

Sample returns on instruments for various horizons (\% annually).

\begin{tabular}{lccc}
\hline Instrument & Horizon & & \\
\cline { 2 - 4 } & 1 year & 5 years & 10 years \\
\hline SPY US Equity & 11.26 & 12.99 & 7.04 \\
ILF US Equity & -9.95 & -2.44 & 15.43 \\
CAC Index & -3.62 & 3.39 & 3.30 \\
SHY US Equity & 0.51 & 0.23 & 0.40 \\
VB US Equity & 5.33 & 15.92 & 10.35 \\
RTSIS Index & -31.62 & -2.53 & 10.53 \\
IGE US Equity & -1.13 & 6.13 & 11.33 \\
SLYV US Equity & 2.82 & 15.12 & 8.53 \\
LQD US Equity & 4.65 & 2.89 & 1.05 \\
IEF US Equity & 3.7 & 3.07 & 2.38 \\
IWN US Equity & 0.64 & 12.74 & 7.93 \\
IVW US Equity & 13.35 & 13.92 & 7.93 \\
EFA US Equity & -6.2 & 4.01 & 4.90 \\
GLD US Equity & -4.72 & 4.54 & 12.11 \\
FT-100 Index & -4.42 & 5.10 & 4.71 \\
NKY Index & 2.65 & 9.54 & 5.96 \\
DAX Index & 1.36 & 10.49 & 10.18 \\
IYT US Equity & 22.77 & 17.55 & 11.87 \\
IBB US Equity & 34.45 & 27.94 & 16.25 \\
\hline
\end{tabular}

Source: authors' calculations based on Bloomberg data.

\footnotetext{
5 The calculations use the values of respective indices for the French, German, Japanese, UK and Russian stock markets, due to the limited historical data of the respective ETFs.
} 
Table 2

Sample standard deviations of instruments over various horizons ( $\%$ annually).

\begin{tabular}{lccc}
\hline Instrument & Horizon & \\
\cline { 2 - 4 } & 1 year & 5 years & 10 years \\
\hline SPY US Equity & 10.76 & 16.04 & 20.40 \\
ILF US Equity & 21.87 & 24.40 & 35.61 \\
CAC Index & 14.61 & 21.67 & 23.09 \\
SHY US Equity & 0.68 & 0.94 & 1.63 \\
VB US Equity & 13.53 & 20.96 & 24.81 \\
RTSI\$ Index & 26.95 & 26.89 & 34.71 \\
IGE US Equity & 14.15 & 22.48 & 30.23 \\
SLYV US Equity & 13.66 & 21.41 & 24.84 \\
LQD US Equity & 4.40 & 5.73 & 8.77 \\
IEF US Equity & 5.02 & 6.74 & 7.05 \\
IWN US Equity & 13.48 & 21.72 & 26.62 \\
IVW US Equity & 11.71 & 15.78 & 19.08 \\
EFA US Equity & 12.03 & 21.11 & 24.77 \\
GLD US Equity & 13.64 & 17.94 & 20.31 \\
FT-100 Index & 10.25 & 15.82 & 19.33 \\
NKY Index & 19.54 & 21.57 & 24.60 \\
DAX Index & 15.06 & 20.28 & 22.21 \\
IYT US Equity & 15.39 & 21.12 & 25.72 \\
IBB US Equity & 25.11 & 21.91 & 22.43 \\
\hline
\end{tabular}

Source: authors' calculations based on Bloomberg data.

assert any reduction in their returns. This result may be due to the market fluctuations that took place during the sample periods (2008-2009 crisis and the increased volatility of the Russian market during 2013 and 2014).

Table 2 contains the calculated standard deviation of average annual returns over the given periods for all instruments, based on daily data. All instruments show increases in the standard deviation as the horizon grows. A logical explanation is that a longer horizon corresponds to a much larger sample of daily returns $(252,1258$, and 2497 values for 1,5 and 10 years, respectively). In turn, this leads to wider ranges in some cases and to more-frequent extreme values within a range in others. As a result, dispersion and standard deviation increase. For example, with the Russian index, the yearly standard deviation was $26.89 \%$ over 5 years and $34.71 \%$ over 10 years. This sharp increase can be explained by the fact that, unlike the first sample, the second includes the 2008-2009 crisis with abnormally high market volatility.

Thus, the data from individual indices show that a longer investment horizon leads to wider potential fluctuations in returns and may result in an increased average annual risk. Over a longer period, returns on various instruments may have values that are extreme within the current historic range or may even break their historic records. This may lead to abnormally low returns for a portfolio with a fixed asset allocation throughout the investment period.

For a more thorough analysis of the hypothesis that as the investment horizon grows, differences in the risk rates of different asset allocation strategies increase, we analyzed the changes in opportunities for global diversification over longer investment horizons. This yielded a clearer understanding of the comparable advantages of long-term allocations of various asset classes belonging to different financial markets. 
An empirical analysis of global diversification between various investment strategies (based on ETF data) and markets was carried out based on a sample of the 19 instruments listed in Table 1.

Based on daily data, we estimated returns and risk rates for 1-, 5-, and 10-year investment horizons. The average annual return on a portfolio with asset allocation $\left(w_{i 1}, w_{i 2}, \ldots, w_{i 19}\right)$ was determined as the average daily return $r_{i}$ on that portfolio over the entire investment period $T$, multiplied by 252 (the standard number of trading days in a year). The average annual risk rate of a portfolio with asset allocation $\left(w_{i 1}, w_{i 2}, \ldots, w_{i 19}\right)$ was calculated as the standard deviation of daily returns on that portfolio over the entire investment period T, multiplied by $\sqrt{252}$ (a standard transformation for a constant value as a part of a standard deviation). Defining portfolio characteristics in this way enabled us to take into account their fluctuations over the entire investment horizon and to reflect their volatility as a standard deviation in the analysis. This is especially significant when comparing various long-term investment strategies and researching opportunities for diversification and for improving the efficiency of long-term investments.

Of the 19 indices above, we obtained a set of portfolios by modeling over 14,000 possible combinations. This set of various asset allocations included the following types of portfolios: average weighted portfolio with the same weight of each asset and portfolios fully (100\%) consisting of each individual asset. The remaining combinations describe most fully varied strategies for longterm asset allocation.

We emphasize some specific portfolios consisting of the stocks (units) of a single index. They include the following: SHY US Equity, as a proxy for the risk-free return rate of short-term government securities; SPY US Equity, as an indicator of returns on the stocks of the 500 largest U.S. issuers listed on the S\&P 500 index; LQD US Equity, as a benchmark of returns on U.S. investment-grade bonds; the portfolio conventionally named "Full Diversification", consisting of stocks (units) of all 19 index portfolios with the same weighting; and the RTS index portfolio.

Fig. 2 displays the frontier for each portfolio set with investment horizons of 1,5 and 10 years. The 1-year portfolios demonstrated a significant dispersion between minimum and maximum returns and risk values. An efficient portfolio set consists of a set of portfolios with annual returns between $0.0 \%$ and $34.3 \%$. Portfolios used as benchmarks - SHY (100\% short-term government securities), LQD (100\% corporate investment-grade securities) and SPY (100\% stocks of the 500 largest U.S. companies) - occupy roughly the same line.

The set of 5-year investment period portfolios maintained a significant dispersion between minimum and maximum returns and risk values; however, the dispersion between returns became significantly narrower than for 1-year portfolios. An efficient portfolio set consists of a set of fund combinations with annual returns between $0.2 \%$ and $27.8 \%$. Portfolios used as benchmarks - SHY, LQD and SPY - are also approximately on the same line here.

As the investment horizon extends to 10 years, the difference between minimum and maximum risk values increases, while the difference between the maximum and minimum average annual returns of the portfolio set decreases. An efficient portfolio set consists of a set of portfolios with annual returns between $0.4 \%$ and $15.9 \%$. None of the possible portfolios with 10 -year investment horizons has 


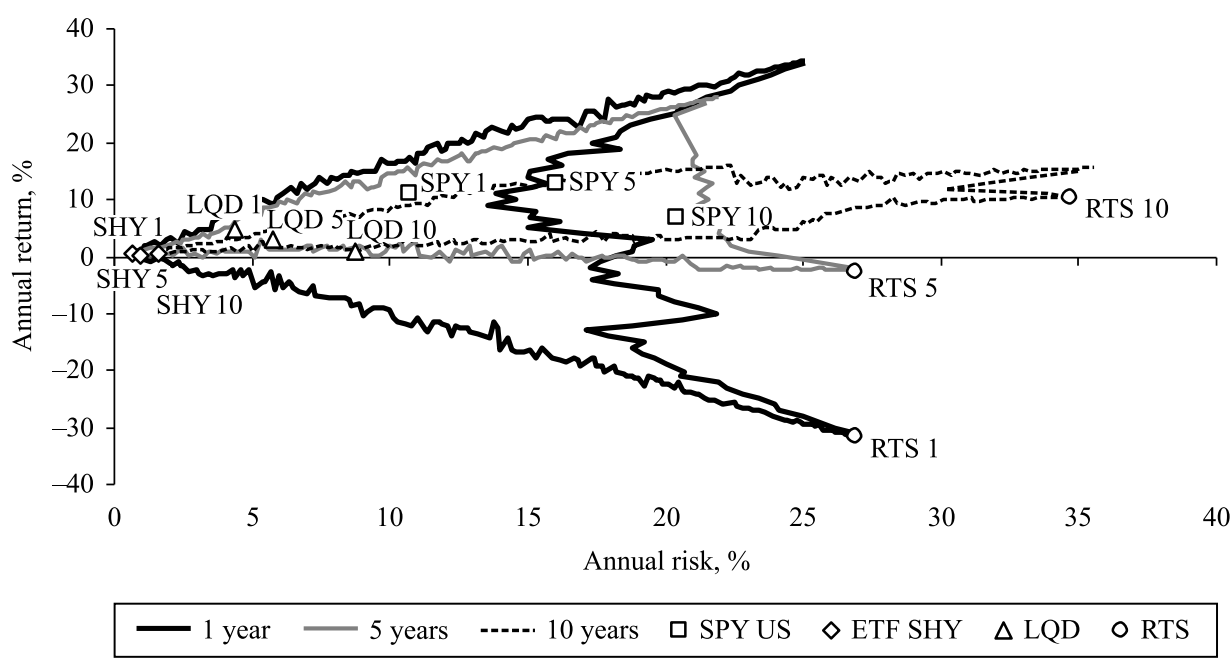

Fig. 2. Frontiers of portfolio sets from 19 equity investment funds (ETFs) and indices with 1-, 5-, and 10-year investment periods.

Note: the numbers next to the asset names indicate the periods of investment in the portfolios fully $(100 \%)$ consisting of those assets (1 year, 5 years and 10 years).

Source: authors' calculations based on Bloomberg data.

a negative average annual return, which per se demonstrates the advantage of diversifying portfolios over time. Portfolios used as benchmarks - SHY, LQD and SPY - are also approximately on the same line here. As the investment horizon increases, the impact of diversification on reducing the correlation between a portfolio's returns and risks falls significantly. Thus, for the risk-return ratio of a portfolio, the allocation of various investment asset classes becomes more relevant than the security selection within those asset classes, which determines to a great extent the portfolio risk and, to a lesser extent, its return.

The overlapping frontiers of portfolio sets and 1-, 5- and 10-year investment horizons clearly demonstrates that a longer investment horizon narrows the dispersion between portfolio returns while increasing the range of the standard deviation.

Table 3 summarizes the data, obtained in an empirical analysis of portfolios, on maximum and minimum risk and return values for portfolios with 1-, 5and 10-year investment horizons. Returns on one-year portfolios vary between $-31.6 \%$ and $+34.3 \%$; the standard deviation varies between $0.5 \%$ and $26.9 \%$. As for 5-year portfolios, with the range of average annual returns on portfolios narrowing to $-2.5 \%$ to $+27.8 \%$, the range of standard deviations of portfolios hardly changed, being $0.9 \%$ to $26.9 \%$. As the investment horizon extends to 10 years,

Table 3

Summary data on returns and risks for portfolios with different investment horizons ( $\%$ annually).

\begin{tabular}{|c|c|c|c|c|}
\hline \multirow[t]{2}{*}{ Horizon } & \multicolumn{2}{|c|}{ Standard deviation (risk) } & \multicolumn{2}{|c|}{ Return } \\
\hline & Min & Max & Min & Max \\
\hline 1 year & 0.5 & 26.9 & -31.6 & -34.3 \\
\hline 5 years & 0.9 & 26.9 & -2.5 & 27.8 \\
\hline 10 years & 1.6 & 35.5 & 0.4 & 15.9 \\
\hline
\end{tabular}

Source: authors' calculations based on Bloomberg data. 
the range of risk values increased to $1.6 \%$ to $35.5 \%$, while the difference between the minimum and maximum average annual return of the portfolio set narrowed to $0.4 \%$ to $15.9 \%$ per year.

Thus, the research, which covered quite a large and representative sample of different investment strategies up to a 10-year horizon, has shown that portfolio sets contract along the return axis and expand along the risk rate axis. This suggests that in long-term investments, the most important objective may be finding the target risk-return ratio of a portfolio and, first of all, the allocation of different classes of investment assets. To examine the sustainability of this hypothesis and to identify the comparative advantages of various asset classes, we will analyze longer investment horizons (up to 30 years) and change the sample of assets.

\section{The impact of longer investment horizons on the comparative advantages of financial instruments}

Fig. 3 shows the results of parameter calculations for Russian financial market instruments. The comparison is between two asset classes and their respective indices: a stock index (MICEX) and a corporate bond index (IFX-bonds). We calculated the rate of return (average annual return) and the risk rate (standard deviation) for each duration of investment period from 1 to 13 years based on daily data from 2002 to 2014 . The traditional theory argues for lower stock risks in the long run and a convergence of that asset class with bonds at a higher return. However, as shown in Fig. 3, stock risks do not decrease even over long investment horizons (up to 10 years and longer), whereas bond risks remain stable and do not depend on the investment period. For investment horizons of over 10 years, stock returns actually exceeded bond returns in the Russian market. However, a comparison between these investments in terms of risk, i.e., average annual standard deviation of daily returns (hereinafter the risk rate), suggests a conclusion that bonds are preferable to stocks even over long-term horizons.
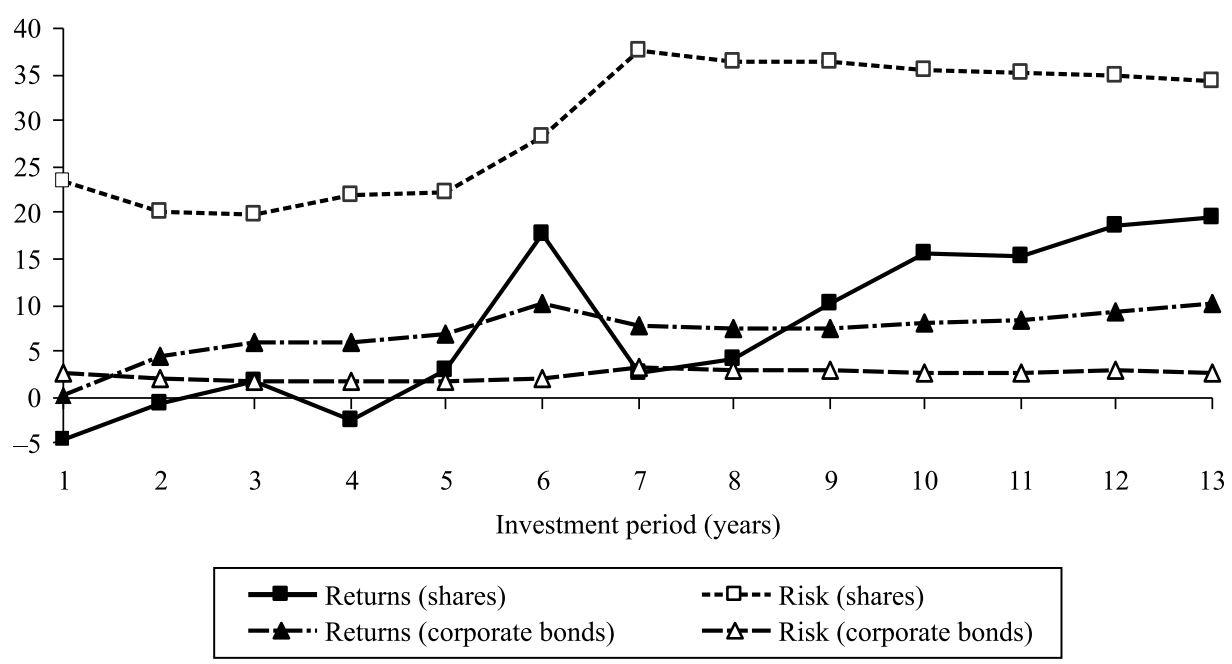

Fig. 3. Returns and risks based on daily return data for portfolios from the MICEX index (stocks) and IFX-bonds (corporate bonds) over longer investment horizons (\% annually). 
To verify the above hypothesis that there is a potential comparative advantage of bonds over stocks over a long-term horizon, similar research was carried out based on longer series of U.S. indices. We used the S\&P 500 as the stock index. As a proxy for bonds, we used the BofA Merrill Lynch US Corporate Index (C0A0), which tracks the trends in investment-grade corporate bonds issued in the domestic U.S. market. Securities within it should:

- be of investment grade (based on average Moody's, S\&P and Fitch rating);

- have at least 18 months of overall maturity;

- have at least 1 year of remaining maturity as of the index re-balancing date;

- have a fixed coupon payment schedule;

- have at least \$250 million of free float.

The index did not include most hybrid corporate bonds. As of 2015, the index included approximately 6500 various bonds from all sectors of the economy, maturing in 1 to 25 years. The index was founded in December 1972 and has quite a long history of daily returns that were obtained from the Bloomberg database. All of the above facts allow us to consider the index as representative of this asset class and to include it in the analysis.

Using data from the two indices, we analyzed the trends for the main indicators of stock and bond portfolios against changing investment horizons from 1 to 30 years, based on daily data from the beginning of 1985 to the end of 2014 .

Fig. 4 shows the movements of parameters for their respective U.S. corporate bond and stock portfolios. For corporate bonds with an increasing investment horizon, we observed relative stability in returns as well as risks. At the same time, the risk rate grows slightly at first for short-term horizons (up to 7 years). The return rate also fluctuates around a slightly positive trend, only demonstrating insignificant growth over long periods. On the whole, we can see that returns exceed the risk rate over long-term investment periods.

The results are the opposite for stocks. The return rate decreases after a 6-year investment period and then fluctuates around a 5-7\% average annual return.

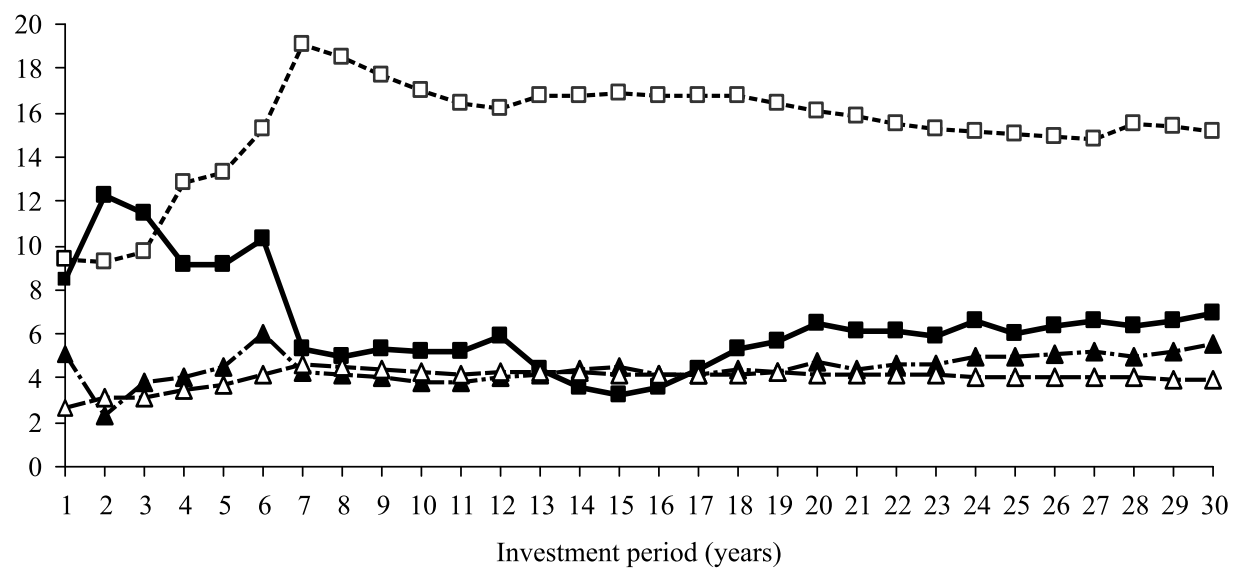

$$
\begin{array}{|ll|}
\hline \rightarrow-\text { Returns (US shares) } & --\square-- \text { Risk (US shares) } \\
-\leftarrow \text {-. Returns (US corporate bonds) } & -\Delta-\text { Risk (US corporate bonds) } \\
\hline
\end{array}
$$

Fig. 4. Parameters of portfolios consisting of a corporate bond index and a U.S. stock index (\% annually). Source: authors' calculations based on Bloomberg data. 
At the same time, the risk rate grows considerably and, after a 7-year period, evens out at a considerably high level compared with the return rate. This means that stocks do not become less risky assets over longer investment horizons. The analysis has demonstrated that this portfolio has a rather low risk-return ratio, i.e., below 1 .

A comparative analysis of the risk and return trends for stock and bond portfolios confirmed the above findings. We can see that the average annual returns on portfolios differed considerably over short-term periods of 1- to 6-year investment horizons. At the same time, quite logically, stock returns exceed bond returns. However, returns on the portfolios under review became much closer over longer periods. Moreover, there are periods where bond returns have exceeded stock returns (14, 15 and 16 years). This suggests that the difference between stock and corporate bond returns disappears over sufficiently long investment horizons.

Of greatest interest is a comparative analysis of portfolios in terms of the risk rate, which was calculated as a yearly standard deviation based on historical daily data for the respective period. We can see that the risk rate for the stock index portfolio grew at first for investment horizons of 1 to 7 years and then, following a slight decrease, remained almost flat. This runs contrary to Siegel's results (Siegel, 2008), according to which the risk rate of stocks decreases to that of bonds in the long run. The risk rate of a corporate bond portfolio remained almost the same for any of the investment horizons and was considerably lower than the stock risk rate for any of the investment horizons.

As shown above, the risks and returns of different financial instruments (stocks and bonds) behave differently over time. Returns on different asset classes become closer, while differences in the risk rate grow rapidly. This suggests that over a longer horizon, stocks do not necessarily become more profitable for an investor in terms of the risk-return trade-off. It has been shown that situations are possible where over long investment horizons (from 15 years onward, as well as 10 years for the Russian market), corporate bonds provide a comparative advantage over stocks in terms of returns and risk rates. This means that this asset class can be viewed as the most promising and preferable for long-term investors with long investment horizons. Moreover, we can recommend increasing the share of bonds in portfolios over longer investment horizons.

\section{Diversification opportunities over long-term investment horizons}

Long investment horizons were analyzed based on a different sample of financial instruments. Increasing the horizon to 30 years required daily data of comparable depth. Only a few stock indices at the financial markets of developed and developing countries possessed this quality.

To carry out an intertemporal analysis, we used a sample of 10 assets that represented global indices with the longest series of data (Table 4). The sample enabled us to collect daily data on their returns for 30 years, from 1984 to 2014. By increasing the length of the series, we were able to evaluate sample correlations and other joint allocation parameters for those assets over periods of 1 to 30 years.

In a similar manner, based on daily data, we calculated the respective series of risk-return pairs for portfolios held by an investor with constant weighting during $t$ years $(t=1, \ldots, 30)$. 
Table 4

Index list.

\begin{tabular}{lll}
\hline Name & Country & Bloomberg ticker \\
\hline Nikkei 225 & Japan & NKY Index \\
Hong Kong Hang Seng Index & Hong Kong & HSI Index \\
Taiwan Stock Exchange Weighted Index & Taiwan & TWSE Index \\
Korea Stock Exchange KOSPI Index & Korea & KOSPI Index \\
Australian Stock Exchange All Ordinaries Index & Australia & AS30 Index \\
Jakarta Stock Exchange Composite Index & Indonesia & JCI Index \\
S\&P 500 Index & United States & SPX Index \\
FTSE 100 Index & United Kingdom & UKX Index \\
Deutsche Boerse AG German Stock Index DAX & Germany & DAX Index \\
AEX-Index & Netherlands & AEX Index \\
\hline
\end{tabular}

For the widest review possible, we compiled various weighted sets for over 10,000 portfolios (10,672 portfolios). This enabled us to more completely evaluate possible asset combinations in investor portfolios and to evaluate the effectiveness of most possible asset allocations. The sets included the "Full Diversification" portfolio, where each of the 10 assets has the same weighting. Additionally, the analysis included portfolios fully (100\%) consisting of each particular asset to be able to evaluate the limits of a portfolio set and pinpoint the location of full diversification in the risk-return space. The remaining weighting sets - various linear combinations of assets in a portfolio - were generated using a random number generation algorithm with the condition that their sum equaled $100 \%$. The large number of portfolios enabled us to present the fullest possible picture of the differences between various asset allocation strategies and to analyze the changes in their comparative advantages over longer investment periods.

The model is presented in Fig. 5. It displays portfolio sets for various investment horizons in coordinates of the risk rate (standard deviation, in \% per year) and rate of return (average annual return, in \% per year). Similar results were obtained for each investment period from 1 to 30 years. However, this article presents only a sample of the clouds on the graphs for periods of $1,5,10,20,25$ and 30 years. Each graph also highlights the location of the portfolio with the same weight of $10 \%$ for each of the instruments reviewed.

As the investment period increases, the portfolio set for the same selection of portfolios contracts vertically. This means that differences between portfolios diminish slightly as the length of time the portfolio is held grows. However, it should be noted that there is no full vertical contraction, even for the longest 30 -year period. The dispersion between return rates stops shrinking roughly after the 20-year mark, which may be due to the cyclical nature of the financial market. For example, decreasing volatility and, as a consequence, the decreasing dispersion between the return-risk parameters, can be explained by transitions of the markets (or some markets out of those reviewed) to the allocation stage. It is characterized by mixed investor sentiment, leading to a reduction in the price amplitude. Hypothetically, this long-term cyclical pattern may be a consequence of long waves in global economic trends, which have a considerable influence on the trends and structures of national financial markets. Returns on a fully diversified portfolio are almost constant for most periods and fluctuate around approximately $6 \%$ annually. 

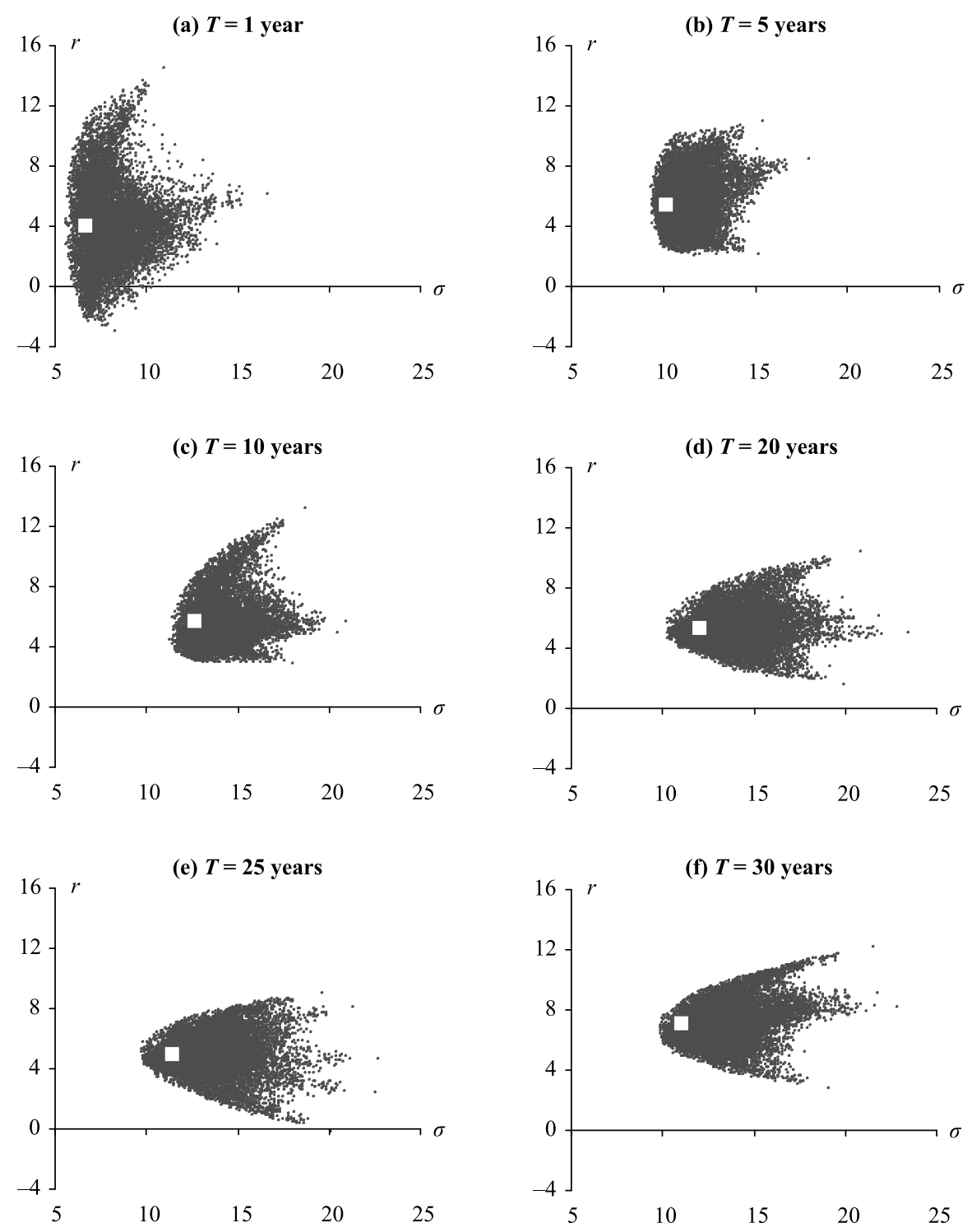

Fig. 5. Portfolio set with an investment period of $T$ years in risk $(\sigma, \%)$ and return $(r, \%)$ coordinates. Note: the 'Full Diversification' portfolio is marked with a white square.

Source: authors' calculations based on Bloomberg data.

In contrast, the differences in the risk rate in the form of standard deviation grow as the investment period increases. The cloud becomes horizontally wider with each 5-year increment. Over the 1-year period, only a few individual portfolios were on the right-hand border of the risk rate. However, as the period grows, more dots appear on the cloud's border. That is, their density increases and, thus, quite a number of portfolios bear increasingly higher risks.

A calculation of the variance between the data series obtained for each investment period duration allowed us to estimate the degree of the dispersion of the portfolios along the $\mathrm{X}$ and $\mathrm{Y}$ axis for each investment period. For example, the variance of the average annual return for 5 -year investment period portfo- 
lios is characteristic of the dispersion between the average annual returns for all of the 10,672 portfolios obtained in the model. Here, dispersion characterizes the presence and extent of differences in returns on portfolios with completely different long-term asset allocations. Similar calculations were made for the risk rate, i.e., the standard deviation for each of the portfolios for each investment period duration. Dispersions of the risk rate were calculated for each $t$ investment period. The calculation results are presented in Fig. 6.

The return dispersion (parameter of the vertical width of a portfolio set in the previous figures) falls considerably beginning with the 18 -year investment period and is generally negatively correlated with the investment period. This fact clearly confirms the hypothesis that the dispersion of the average annual return falls as the portfolio investment period increases. Thus, if investors each held one portfolio from the set for one year, their effectiveness would differ dramatically. This was previously demonstrated in the figure containing a respective portfolio set. The analysis helped us verify the previous quantitative hypotheses. For 1 -year investment period portfolios, dispersion reaches $7.5 \%$, while the average (not shown in the graph) is approximately $4.0 \%$. This means that, on average, most dots (returns on different portfolios) fall within the following interval according to the "three sigma" rule: $[4-3 \times \sqrt{7.5}, 4+3 \times \sqrt{7.5}]=[-4.22,12.22]$.

The dispersion of returns for portfolios with a 30 -year investment period is not the least among dispersions for all periods under review, as was expected according to the dispersion contraction hypothesis. However, it is still representative. The dispersion of returns on portfolios with a 30 year period is approximately $2 \%$, with an average of $7 \%$. Thus, with moderate growth in the mean interval value of all returns obtained for all portfolios under review, we observed a sharp decline in dispersion between these returns around an average value for all types and asset allocations. Here is an evaluation of the interval according to the same "three sigma" rule: $[7-3 \times \sqrt{2}, 7+3 \times \sqrt{2}]=[2.76,11.24]$. Negative returns are no longer seen, while the return dispersion interval had its low limit shifted upward by more than 6 percentage points compared with the 1-year portfolios.

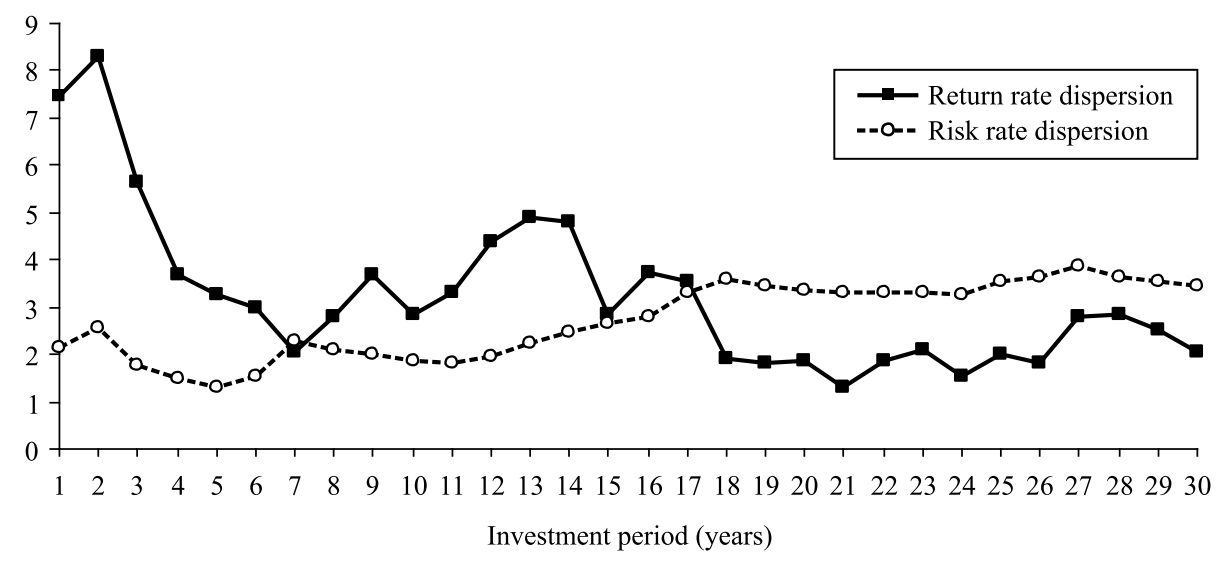

Fig. 6. Dispersion of the average annual return and risk rate for all portfolios and different investment periods (\%).

Source: authors' calculations based on Bloomberg data. 
The risk rate shows a positive trend. The quantitative analysis has confirmed the results of the graphical analysis. Longer investment periods for the same portfolios lead to a growth in risk rate differences between them. Thus, over short periods, dispersion of the risk rate may play a secondary role in determining the optimal strategy of asset allocation. However, beginning from the 16-year horizon, one should take into account the comparative advantages of various portfolios in terms of the risk rate on par with the other factors.

As shown above, differences in average returns across portfolios decrease as the investment period grows, while differences between the risk rates of portfolios with different asset allocations increase. Asset allocation in this analysis is a sample set of weightings for a long-term period. Fig. 6 shows that dispersions between risk rates and return rates are almost equal at the 17-year investment horizon. This results in an almost round-shaped cloud of portfolios in the graph's risk-return coordinates. Before the 17-year point, the return rate dispersion is always greater than the risk rate one. Therefore, over short- and medium-term investment horizons, an investor should be guided mainly by optimizing the desired return criteria, and only then by the risk rate. However, beginning from the 17-year period, the risk rate dispersion exceeds the return rate one, suggesting that asset allocation has a greater impact on differences in the risk rate than returns over long-term horizons. Therefore, for long investment horizons, it is especially important to determine a long-term asset allocation that would pose a lower risk. We can take into account target indicators of returns as a secondary objective, as differences in returns are partly eliminated over long horizons.

According to the findings regarding the long-term attractiveness of corporate bonds, we analyzed the joint hypothesis about the growth in differences between risk rate values for asset allocation strategies with increasing investment periods as well as the hypothesis about the comparative advantage of stocks over bonds in the long run. These hypotheses were tested using the same set of 10 assets listed in Table 4, except for the Dutch AEX-Index. Instead of that index, the $10^{\text {th }}$ asset was the BofA Merrill Lynch US Corporate Index (COA0) of the corporate bonds.

The modeling results for over 10,000 different asset allocations for various sample investment horizons $(1,5,10,20,25$ and 30 years) are shown in Fig. 7. The figure highlights the portfolio fully $(100 \%)$ consisting of the corporate bond index (simulating a U.S. corporate bond portfolio) and the portfolio fully consisting of the S\&P 500 Index (simulating a U.S. stock portfolio). We can see that the portfolio set for each investment period has a more oblong shape along the horizontal axis than in Fig. 5. This can be explained by the inclusion of the bond index in the calculation, which is more to the left, in the zone of the lowest risk, and has roughly average returns among all of the portfolios reviewed. The figure demonstrates the relative safety of investing in this asset compared with investments in stocks, regardless of the geographic location of the financial market.

Changes in the characteristics of a portfolio fully consisting of the S\&P 500 Index over a longer investment horizon can also be seen in Fig. 7. Over shortterm investment periods ( 1 and 5 years, Fig. 7a and 7b, respectively), its risk and return far exceed the same parameters for the corporate bond portfolio. However, over investment periods of 10 and 20 years (Fig. 7c and 7d, respectively), differences in the average annual returns almost disappear (stocks yield only a little more than corporate bonds), whereas differences in the risk grow considerably. 

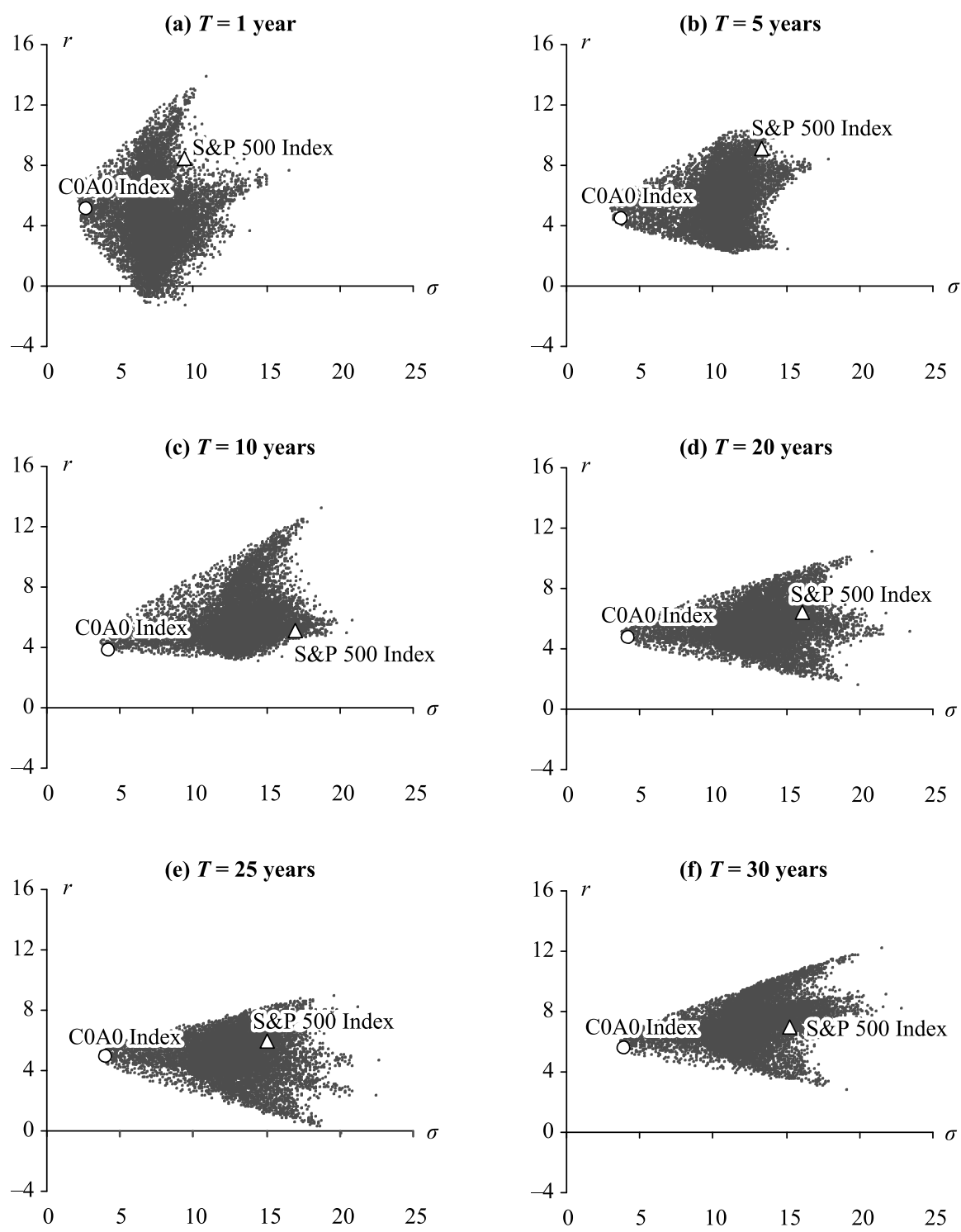

Fig. 7. The portfolio set including corporate bond index with a $T$ investment period in risk $(\sigma, \%)$ and return $(r, \%)$ coordinates.

Note: the white circle marks the corporate bond index portfolio; the white triangle marks the S\&P 500 Index portfolio.

Source: authors' calculations based on Bloomberg data.

As the period is extended, extreme values in daily returns increased their range and occurred more often. This had the effect of increasing dispersion and risk rates. Over a long-term period (Fig. 7e and 7f), the risk rate declined a little, though it was still three times higher than the bond portfolio risk, while differences in the average annual returns were small.

The shape of the portfolio set is more oblong than in Fig. 5. In addition, we can see that it changes similarly as the investment period increases. For the 1-year horizon, the cloud is rounder, with greater differences in the average annual returns as well as in the risk rates among all of the reviewed asset allocations. 
The portfolio set over a 5-year horizon is more oblong, but to the left and to the right there are still significant differences in the average annual returns between portfolios within the same risk zone. An even more oblong shape is characteristic of longer investment horizons, while in the left-hand part of the cloud, consisting of portfolios with minimum risks and different weightings $(>>0)$ of corporate bonds, differences in the average annual returns decrease sharply as $\mathrm{T}$ grows. This results in the almost triangular shape of the cloud on the left. On the right, as the horizon grows, the spokes protruding in the direction of the edges take on more pronounced shapes (the right edges of the cloud represent portfolios fully $(100 \%)$ consisting of the various global stock indices from Table 4$)$. Thus, the locations of portfolios on the right along the horizontal axis are more scarce along the vertical axis (average annual return), while differences between many portfolios disappear, resulting in a denser middle of the cloud with clearly defined spokes on the edges with minimal dispersion between the dots around them.

The visual presentation of the results can be seen in Fig. 8 as a quantitative evaluation of the protruding parameters of portfolio sets along the axes. For each investment period, we calculated dispersion for all data series.

The trends for both series differ significantly in amplitude from Fig. 6, which does not include corporate bonds. The differences in the dispersion series are more significant. Only within the shortest periods do the differences in average annual returns prevail over differences in the risk rates. This is shown in Fig. 7 as an almost round-shaped portfolio set that is heavily pinched along the horizontal axis. Beginning from the 4-year investment horizon, the leading role is taken by differences in the risk rates, while return differences between asset allocations decrease as the investment horizon grows. There are periods of growth in return rate dispersion; however, we can say that it fluctuates around a negative trend line. Risk rate dispersion, representing a characteristic of the cloud's oblongness along the horizontal axis, increases quickly up to the 18-year period and then fluctuates around that level. The increase in investment periods for the same portfolios leads to a substantial increase in the differences between them in terms of the risk rates, while differences in the return rates decrease. Therefore, as

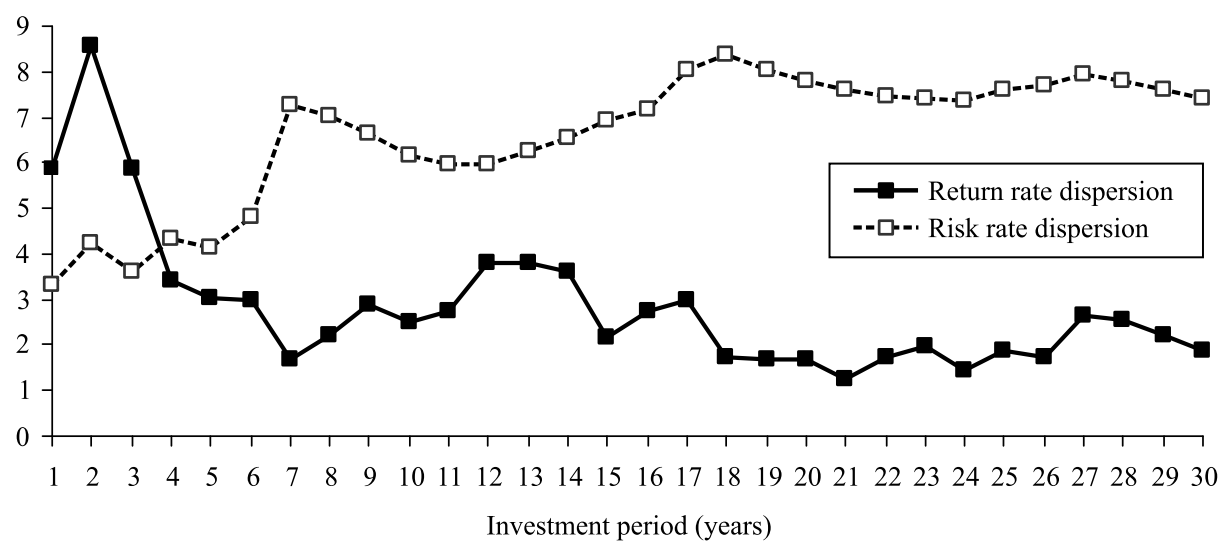

Fig. 8. The dispersion between the average annual returns and the risk rates for all portfolios and different investment periods, taking into account corporate bonds (\%).

Source: authors' calculations based on Bloomberg data. 


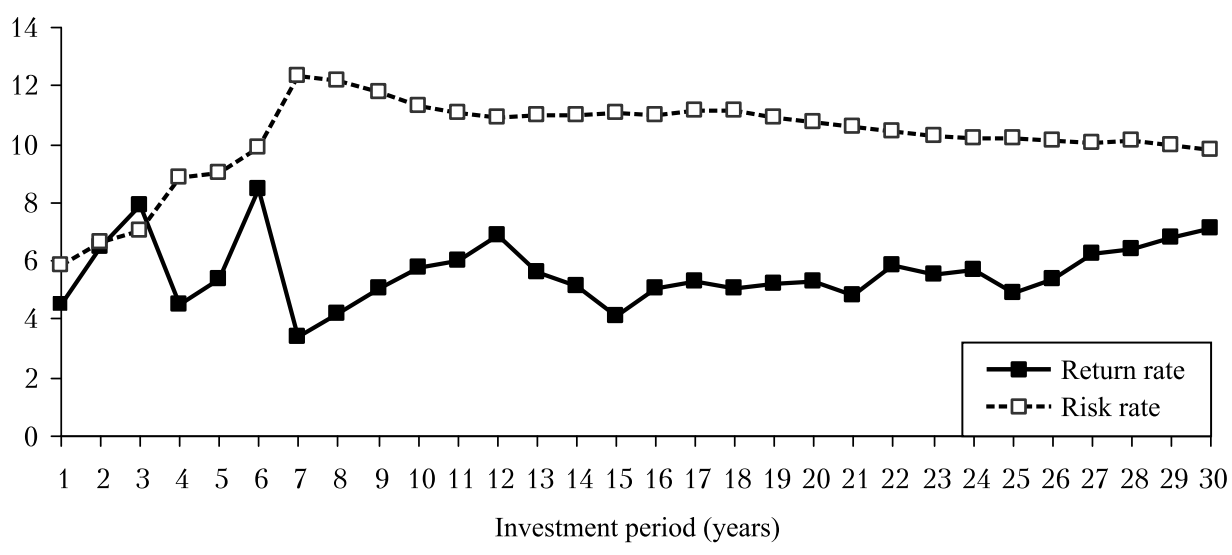

Fig. 9. "Full Diversification" portfolio parameters (\% annually).

Source: authors' calculations based on Bloomberg data.

the portfolio holding period increases, asset allocation between stocks and bonds takes on the greatest importance. Over long-term horizons, asset allocation has a heavier impact on differences in the risk rate than in the return rate.

The trends for a diversified portfolio with equal weightings on all 10 assets (full diversification: 10\% in the corporate bonds index, 10\% in the S\&P 500 Index and $10 \%$ in 8 stock indices of various countries) are shown in Fig. 9. The average weighted portfolio represents an interim value between the stock and corporate bond portfolios reviewed in Fig. 3. It should be noted separately that on the 28-, 29- and 30-year horizons, the average annual returns of the average weighted portfolio and the stock portfolio are almost equal. The return rate fluctuates within the same corridor; it does not grow as the horizon increases. The diversified portfolio shows a slight decline in the risk rate over long investment periods; however, it still considerably exceeds the return rate.

\section{Conclusion}

Identifying a pattern in the behavior of diversified portfolios leads to a number of practical conclusions. In contrast with the traditional approaches of portfolio management theory, assuming that over long-term investment horizons stock investments are more preferable than bonds in terms of the risk-return ratio, the method used in this article has proven the opposite assumption. As horizons increase, stocks and bonds become closer in terms of returns, while stock risks increase faster than bond risks. This means that for long-term investors, investments in corporate bonds are more profitable in terms of the risk-return ratio than investments in stocks. At the same time, the sustainability of these findings has been confirmed both in the case of the Russian financial market with shorter horizons and in the case of developed markets with a longer history.

In the case of diversified portfolio sets, we proved the assumption that over increased investment horizons, investors must pay with a significantly larger increment of the risk rate for each incremental unit of return. This suggests that portfolio management should pay the most attention to risk mitigation. When deciding on a long-term investment strategy for a period of more than 20 years, one should con- 
sider the inherent risks in each potential asset class within a portfolio. For a long investment horizon (10 years or longer), while building an investment strategy, longterm investors should focus more on the asset allocation structure than on selecting particular investment and trading strategies or on particular issues of securities representing respective asset classes. The asset allocation structure should provide for achieving a desired level of return while taking reasonable risks.

The specific behavior of a portfolio set and diversified portfolios over time are the contraction of returns with substantially larger differences in the risk rates. Therefore, we can recommend that long-term investors (government as well as private) periodically restructure their diversified portfolios as the holding period grows. The share of risky assets should be reduced, as their heavy weighting in a long-term portfolio may actually lead to maintaining the same rate of return with a constant, disproportionate increase in the risk.

In our opinion, these assumptions justify the expedience of focusing retirement savings portfolios and private pension funds reserves mostly on the bonds of various issuers, including infrastructural bonds, which are also more in line with the nature of the obligations of this type of institutional investors. Taking into account the problem of the influence of investment horizons on the risk-return profiles of a given portfolio and its ambiguity as perceived by investors and academic circles, regulators should improve disclosure practices regarding the risks and returns of retirement savings portfolios and reserves as well as the particular corresponding asset class components within, including long-term historical indicator data series. This will foster research in this field and, consequently, help justify applied solutions for portfolio investments.

\section{References}

Abramov, A. E. (2014). The institutional investors in the world: Particularities of activities and development policy (In 2 books). Book 1. Moscow: Delo (In Russian).

Abramov, A., Radygin, A., \& Chernova, M. (2014). Financial markets regulation: Models, evolution, efficiency. Voprosy Ekonomiki, 2, 33-49 (In Russian).

Abramov, A., \& Chernova, M. (2015). Analysis of the effectiveness of pension and mutual fund portfolios in Russia (Preprint No. 2015/02). Moscow: RANEPA (In Russian).

Abramov, A., Radygin, A., Chernova, M., \& Akshenntseva, K. (2015). Effectiveness of pension saving management: Theoretical and empirical aspects. Voprosy Ekonomiki, 7, 26-44 (In Russian).

Berzon, N. I., \& Teplova, T. V. (eds.) (2013). Innovations in financial markets. Moscow: HSE Publ. (In Russian).

Brinson, G. P., Hood, L. R., \& Beebower, G. L. (1986). Determinants of portfolio performance. Financial Analysts Journal, 42 (4), 39-44.

Brinson, G., Singer, B., \& Beebower, G. (1991). Determinants of portfolio performance II. Financial Analysts Journal, 47 (3), 40-48.

DeLong, B. J., \& Magin, K. (2009). The U.S. equity return premium: Past, present, and future. Journal of Economic Perspectives, 23 (1), 193-208.

Fisher, L., \& Lorie, J. (1964). Rates of return on investment in common stock. Journal of Business, 37 (1), 1-21.

Ibbotson, R. G., \& Kaplan, P. D. (2000). Does asset allocation policy explain 40, 90, or 100 percent of performance? Financial Analysts Journal, 56 (1), 26-33.

Ibbotson, R., \& Chen, P. (2003). Stock market returns in the long run: Participating in the real economy. Financial Analyst Journal, 59 (1), 88-98.

Ilmanen, A. (2003). Expected returns on stocks and bonds. The Journal of Portfolio Management, $29(2), 7-27$. 
Markowitz, H. (1952). Portfolio selection. The Journal of Finance, 7 (1), 77-91.

Markowitz, H. (1995). Portfolio selection. Oxford: Blackwell.

Mehra, R., \& Prescott C. (1985). The equity premium: A puzzle. Journal of Monetary Economics, 15 (2), 145-162.

Poterba, J., \& Summers, L. (1988). Mean reversion in stock returns: Evidence and implications. Journal of Financial Economics, 22 (1), 27-60.

Radygin, A. D. (Ed.) (2015). The economics of investment funds. Moscow: Delo (In Russian).

Robertson, D., \& Wright, S. (1998). The good news and the bad news about long-run stock market returns. Cambridge Working Papers in Economics, 9822.

Sharpe, W. (1970). Portfolio theory and capital markets. N. Y.: McGraw-Hill.

Sharpe, W. F. (1992). Asset allocation: Management style and performance measurement. Journal of Portfolio Management, 18 (2), 7-19.

Siegel, J. (1992). The equity premium: Stock and bond returns since 1802. Financial Analysts Journal, 48 (1), 26-36.

Siegel, J. (1999). Stocks, bonds, the Sharpe ratio, and the investment horizon: A comment. Financial Analysts Journal, 55 (2), 7-8.

Siegel, J. (2005). Perspectives on the equity risk premium. Financial Analysts Journal, 61 (6), 61-73.

Siegel, J. (2008). Stocks for the long run. The definitive guide to financial market returns and longterm investment strategies (4 ${ }^{\text {th }}$ ed.). N. Y.: McGraw Hill. 